\title{
Lessons learnt from malaria epidemics in the Islamic Republic of Iran
}

\author{
A. Ostovar, ${ }^{1,5}$ A. Raeisi, ${ }^{1,2}$ A.A. Haghdoost, ${ }^{3}$ M. Ranjbar, ${ }^{2}$ A. Rahimi, ${ }^{7}$ K. Sheikhzadeh ${ }^{4}$ and R. Majdzadeh ${ }^{1,5}$
}

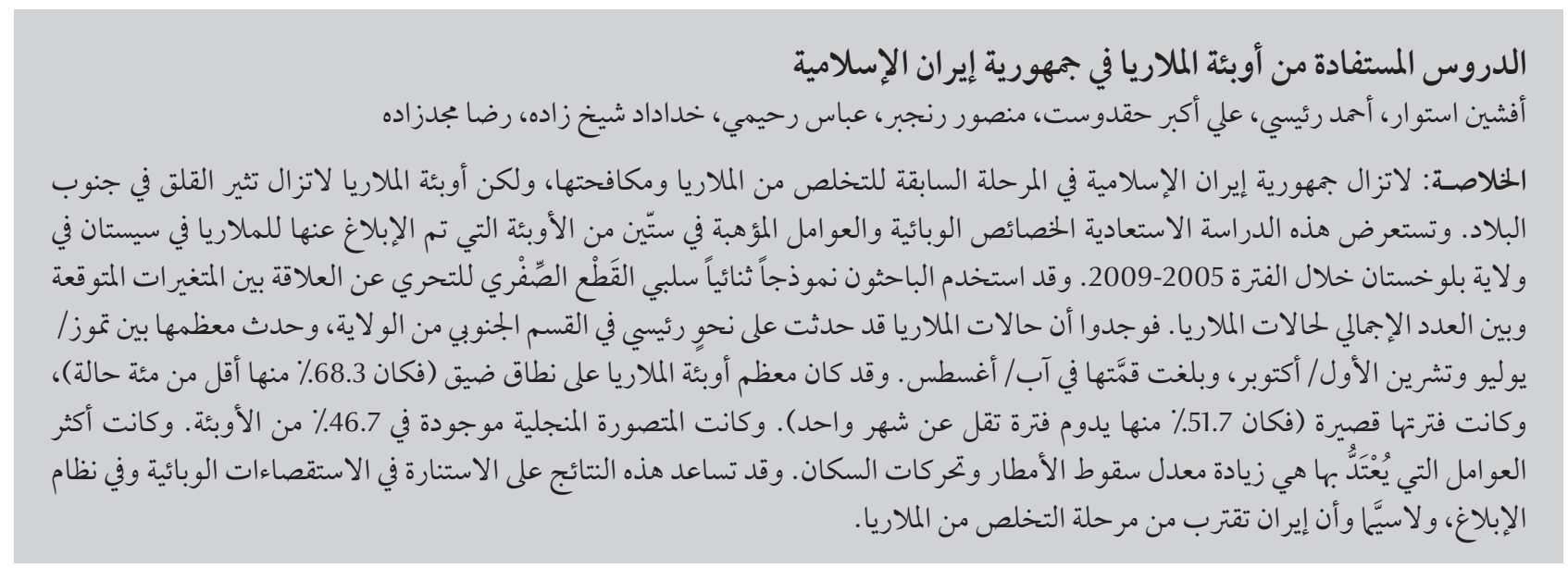

ABSTRACT The Islamic Republic of Iran is in the pre-elimination phase of malaria control, but malaria epidemics are still a concern in the south of the country. This retrospective study presents the epidemiological characteristics and predisposing factors of 60 of the malaria epidemics reported in Sistan va Baluchestan province during 2005-09. A zero-truncated negative binomial model was used to investigate the relation between predictor variables and the total number of malaria cases. Malaria epidemics occurred mainly in the southern part of the province, mostly between July and October, peaking in August. Most malaria epidemics were small-scale $(68.3 \%$ were $<100$ cases) and short (51.7\% lasted $<1$ month). Plasmodium falciparum was present in $46.7 \%$ of the epidemics. An increase in the rainfall rate as well as population movements were the most significant predisposing factors. The results may help inform an epidemic investigation and reporting system as the country approaches the malaria elimination phase.

\section{Enseignements tirés des épidémies de paludisme en République islamique d'Iran}

RÉSUMÉ La République islamique d'Iran se situe dans la phase de pré-élimination du paludisme, toutefois les épidémies restent une préoccupation dans le sud du pays. La présente étude rétrospective livre les caractéristiques épidémiologiques de 60 épidémies de paludisme notifiées entre 2005 et 2009 dans la province du Sistan-Baloutchistan et leurs facteurs prédisposants. Un modèle négatif binomial tronqué en zéro a été utilisé pour étudier la relation entre les variables prédictives et le nombre total de cas. Les épidémies de paludisme ont éclaté principalement dans le sud de la province, surtout entre juillet et octobre, avec un pic en août. La plupart des épidémies étaient de faible envergure (68,3\% portaient sur moins de 100 cas) et de courte durée (51,7\% ont duré moins d'un mois). Plasmodium falciparum était présent dans 46,7 \% des épidémies. Une augmentation de la pluviométrie et les mouvements de population étaient les facteurs prédisposants les plus importants. Les résultats peuvent être utiles pour alimenter une enquête épidémique et un système de notification alors que le pays se rapproche de la phase d'élimination du paludisme.

${ }^{7}$ School of Public Health; ${ }^{5}$ Knowledge Utilization Research Centre, Tehran University of Medical Sciences, Tehran, Islamic Republic of Iran (Correspondence to A. Ostovar: aostovar@razi.tums.ac.ir).

${ }^{2}$ Centre for Communicable Disease Control, Tehran, Islamic Republic of Iran.

${ }^{3}$ School of Public Health, Kerman University of Medical Sciences, Kerman, Islamic Republic of Iran.

${ }^{4}$ Disease Control Department, Zahedan University of Medical Sciences, Zahedan, Islamic Republic of Iran.

Received: 01/12/10; accepted: 06/03/11 


\section{Introduction}

The Islamic Republic of Iran is in the preelimination phase of malaria control, in which elimination and prevention of its reintroduction are the main objectives [1]. Successful implementation of malaria control measures has resulted in a major decline in malaria incidence in the country in the last decade [2]. After considering the positive results of a feasibility study of malaria elimination strategies in line with World Health Organization advice, and after receiving the approval of the Iranian Ministry of Health and Medical Education, the Malaria Control Department planned to eliminate malaria from the country within a few years. This programme, begun in 21010, aimed to eliminate local transmission of Plasmodium falciparum by 2014 and local transmission of malaria in general by 2025 . Among the main strategies to achieve these goals are the implementation of a comprehensive system to predict upcoming malaria epidemics based on predisposing factors and the provision of the required capacity for preventing the disease and planning an effective response to epidemics [3].

A malaria epidemic is defined as an unexpected increase in the number of malaria cases at a particular time and place [4]. Such epidemics are considered as health emergencies, placing a heavy burden on the health status of the affected population $[5,6]$, mainly because they often occur without warning [7]. Low-endemic areas are more prone to malaria epidemics as the transmission rate is low and there are long inter-epidemic periods [6]. Previous studies in the Islamic Republic of Iran have described the overall malaria situation $[8,9]$, investigated the relationship between meteorological variables and malaria incidence, assessed the feasibility of malaria early warning systems [10], and designed a spatial model of malaria incidence [11]. These researches, however, have studied the overall incidence of malaria rather than its epidemics. Therefore, many issues concerning malaria epidemics in the country remain unsolved. These include the lack of an ongoing, comprehensive epidemic reporting system about where and when such epidemics occur and the number of people affected, and a lack of knowledge about the predisposing factors for epidemics.

Sistan va Baluchestan province, which reports about $60 \%$ of all the country's malaria cases, is the main area for local malaria transmission in the Islamic Republic of Iran [9]. This province borders Pakistan and Afghanistan, where there is considerable cross-border population movement. Annually, a number of malaria epidemics occur within the province. The main purpose of this study was to describe the epidemiological characteristics and predisposing factors of the malaria epidemics reported from this province over a 5-year period.

\section{Methods}

Data were collected for a 5-year period (2005-09) in Sistan and Baluchestan province, during which 60 epidemics were recorded. To increase the sensitivity of the definition of epidemic, we considered an epidemic to be any sharp rise of malaria cases in a focus which was greater than the expectations of local health staff for that specific time and place.

For each epidemic which was recorded and reported we asked local health staff to complete a form to record the time, location and duration of the epidemic, total number of malaria cases, number of $P$. falciparum and $P$. vivax cases and the transmission type (local transmission or imported). An imported case is a case who has a history of travelling to an infected area (outside or inside the country) other than the area of investigation within 2 weeks before the diagnosis. Staff were also asked to review their records on reported epidemics for the presence of certain predisposing factors, including: population movements, drought, social conflicts, environmental manipulations, agricultural interventions, abnormal or unexpected rainfall, appropriate humidity and temperature and/or abnormal wind. These were based on the records of epidemic investigation reports available in the local health system.

Considering the overdispersion of the data (i.e. the variance was greater than the mean) and this fact that epidemics with no cases are meaningless, a zero-truncated negative binomial model was used to analyse the association between the predisposing factors and total malaria cases as an index for determining the intensity of malaria epidemics. The incidence rate ratio (IRR) is the ratio of the number of cases in those epidemics which have a certain factor over those which do not, adjusted for other factors. Variable entered in the model and therefore adjusted for were: population movements, drought, social conflicts, environmental manipulations, agricultural interventions, abnormal or unexpected rainfall, appropriate humidity and temperature and/or abnormal wind. Sensitivity of the variables was calculated in order to estimate the predictability of each predisposing factor to accurately predict the incidence of the malaria epidemic.

\section{Results}

The monthly distribution of the malaria epidemics is shown in Figure 1. No epidemics were reported between December and March. The majority of epidemics occurred between July and October, peaking in August. A small rise was reported in May. There was also another peak in October, after a sharp drop in September.

The geographical distribution of the epidemics in different districts is shown in Figure 2. Malaria epidemics mostly occurred in the southern part of the 


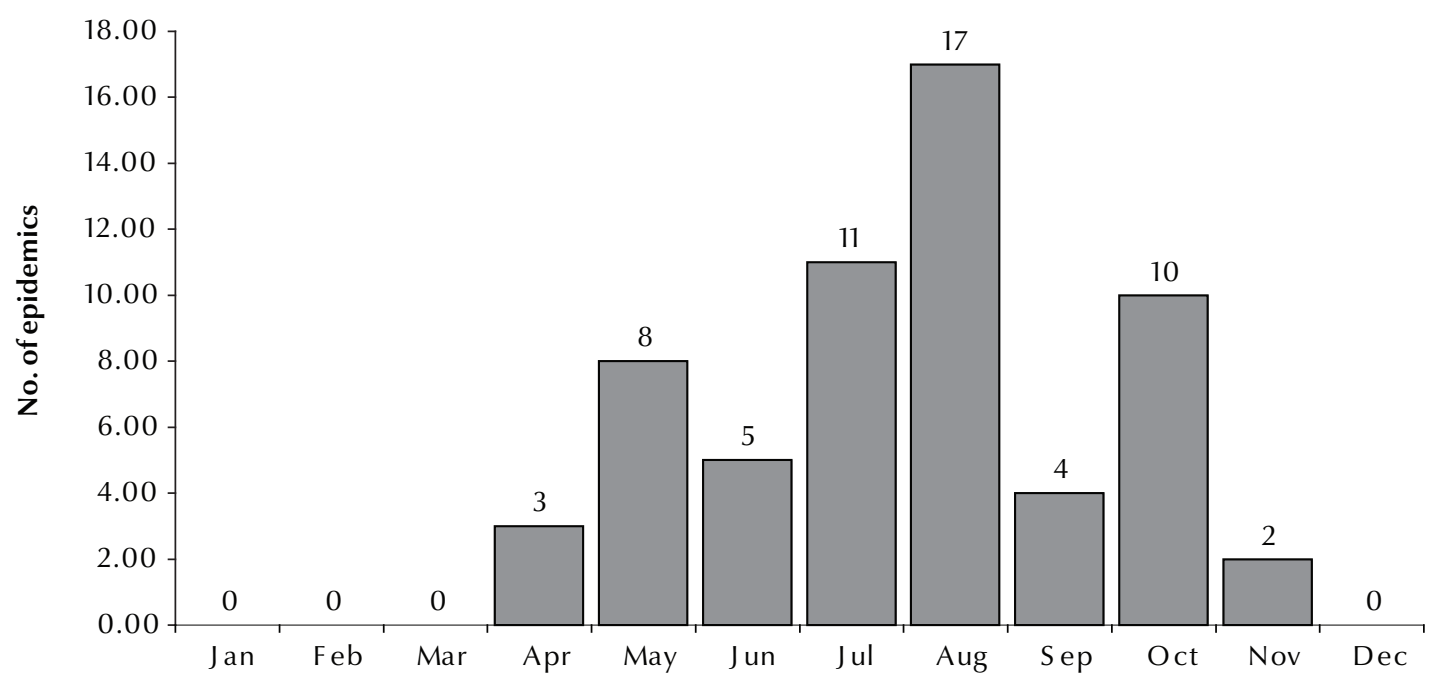

Figure 1 Monthly distribution of the 60 malaria epidemics in Sistan va Baluchestan province, 2005-09

province in Chahbahar, Nikshahr and Sarbaz districts.

Table 1 shows the total number of affected cases and the duration of the epidemics. Most malaria epidemics were small-scale outbreaks $[41 / 60$
$(68.3 \%)$ involved $<100$ cases] and of short duration $[31 / 60(51.7 \%)$ lasted $<1$ month].

In just over half of epidemics (32/60), P. vivax was the only parasite, while P. falciparum, alone or in

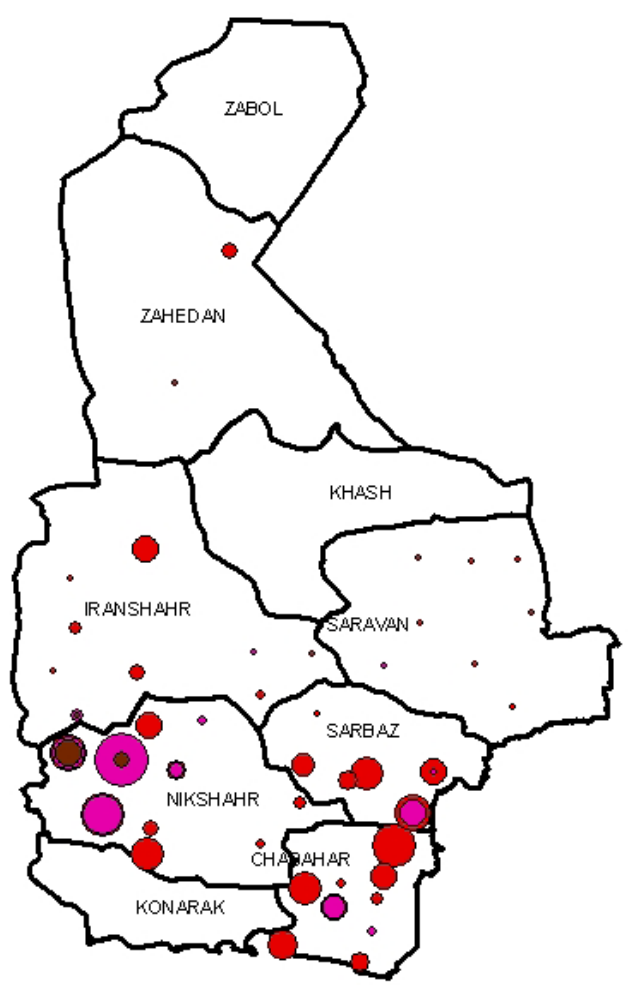

Figure 2 Geographical distribution of the 60 malaria epidemics in Sistan va Baluchestan province, 2005-09 (symbols are proportional to size of epidemics as total malaria cases in each epidemic)

association with $P$. vivax, was reported in $28 / 60$ (46.7\%) of the studied malaria epidemics (Table 2). Locally transmitted cases were seen in nearly all the epidemics (59/60). Pearson chi-squared test revealed a significant association between the presence of imported cases and $P$. falciparum as the underlying cause in these epidemics $(P<0.02)$.

The frequency of the 12 investigated predisposing variables in the epidemics is shown in Table 3. Population movement was the most frequent factor among the studied vulnerability factors, recorded in 42/60 (70.0\%) of epidemics. Meteorological variables such as abnormal or unexpected rainfall (in $60.0 \%$ of epidemics), appropriate temperature $(76.7 \%)$ and appropriate humidity (71.7\%),also frequently accompanied malaria epidemics.

The number of malaria cases in epidemics where the variables were present and not present are also shown in Table 2 and the final columns of the table show the result of zero-truncated negative binomial model for determining the association between predictor variables and the total number of malaria cases in the epidemics. Rainfall was positively associated with the size of epidemic (adjusted IRR 3.64; 95\% CI: 1.64-9.06), while the population 


\begin{tabular}{|c|c|c|c|c|c|c|}
\hline \multirow[t]{2}{*}{ Variable } & \multirow{2}{*}{$\begin{array}{l}\text { No. of } \\
\text { epidemics }\end{array}$} & \multirow[t]{2}{*}{$\%$} & \multicolumn{4}{|c|}{ Sensitivity (\%) } \\
\hline & & & Population movement & Rainfall & Temperature & Humidity \\
\hline \multicolumn{7}{|c|}{ Size of epidemic (no. of cases) } \\
\hline$<10$ & 16 & 26.7 & 81.3 & 31.3 & 68.1 & 75.0 \\
\hline $10-49$ & 16 & 26.7 & 87.5 & 43.8 & 81.3 & 87.5 \\
\hline $50-100$ & 9 & 15.0 & 44.4 & 77.8 & 77.8 & 55.6 \\
\hline$>100$ & 19 & 31.7 & 57.9 & 89.5 & 78.9 & 68.4 \\
\hline \multicolumn{7}{|c|}{ Duration of epidemic (days) } \\
\hline $1-30$ & 31 & 51.7 & 74.2 & 51.6 & 80.6 & 77.4 \\
\hline $31-60$ & 17 & 28.3 & 76.5 & 70.6 & 64.7 & 58.8 \\
\hline $61-90$ & 8 & 13.3 & 37.5 & 87.5 & 75.0 & 75.0 \\
\hline$>90$ & 4 & 6.7 & 75.0 & 25.0 & 100.0 & 100.0 \\
\hline Total & 60 & 100.0 & 70.0 & 60.0 & 76.7 & 73.7 \\
\hline
\end{tabular}

movement negatively affected the size of epidemic (adjusted IRR 0.42; 95\% CI: 0.18-0.98).

Table 1 also shows the sensitivity of the 4 main predictors of malaria epidemics, based on their size and duration. The sensitivity of population movements as a predictor decreased from $81.3 \%$ in epidemics with $<10$ cases to $57.9 \%$ with $>100$ cases. The sensitivity of rainfall as a predictor rose from $31.3 \%$ to $89.5 \%$ respectively (Table 1 ). The sensitivity of humidity and temperature were similarly high for small and large epidemics. There was no pattern in the data indicating an association between duration of epidemics and the sensitivity of predisposing factors to predict malaria epidemics.

\section{Discussion}

Our results revealed that malaria epidemics in Sistan va Baluchestan were characterized by mainly small and short outbreakswithatemporalandspatialpattern. In addition, rainfall, temperature, humidity and population movements were the most frequent predisposing factors contributing to such epidemics. Rainfall was positively associated with the size of epidemics, while population movements were negatively associated with epidemic size.

Our study suffered from certain limitations. First, it only assessed malaria epidemics that had been detected and reported by the health system. It is therefore possible that smaller outbreaks were overlooked. Secondly, epidemics were defined simply as a higher than expected incidence of reported malaria cases, and so the exact criteria used to report an epidemic was not defined. Finally, we only investigated distal determinants of malaria epidemics such as social and meteorological factors rather than proximal predictors such

\begin{tabular}{|c|c|c|c|}
\hline \multicolumn{4}{|c|}{$\begin{array}{l}\text { Table } 2 \text { Presence of imported cases of malaria and Plasmodium falciparum cases } \\
\text { in the } 60 \text { epidemics in Sistan va Baluchestan province, Islamic Republic of Iran, } \\
\text { 2005-09 }\end{array}$} \\
\hline \multirow[t]{2}{*}{ Epidemics with $P$. falciparum cases } & \multicolumn{3}{|c|}{ Epidemics with imported cases } \\
\hline & No & Yes & Total \\
\hline No & 10 & 22 & 32 \\
\hline Yes & 2 & 26 & 28 \\
\hline Total & 12 & 48 & 60 \\
\hline
\end{tabular}

$P<0.02$.

as vector populations and man-vector exposure.

In our study, malaria epidemics mostly occurred between July and October, peaking in August. Another peak was also reported in May; this peak, however, was not as high as the other one. Salehi et al. reported the same pattern for malaria in the same province during 2005-08 [9]. No epidemic, though, was reported between December and March. This might be due to the limiting influence of temperature in this period, which is usually lower than the minimum temperature required for the development of sporozoites. There was also another peak in October, after a sharp drop in September. We cannot suggest any meaningful explanation for this. It might have occurred by chance or as the result of under-reporting of malaria epidemics in September.

Most malaria epidemics were small outbreaks of $<100$ cases and just over $50 \%$ of them resolved in $<1$ month. The density of epidemics was higher in southern districts. Larger epidemics mostly occurred in Chahbahar, Nikshahr and Sarbaz districts, which tend to have the highest malaria infection rates [9]. Smaller outbreaks still occurred in other places in the province. There seemed to be a spatial correlation between the incidence of malaria and the development of epidemics, as both 


\begin{tabular}{|c|c|c|c|c|c|}
\hline \multirow[t]{2}{*}{ Variable } & \multicolumn{2}{|c|}{ Variable present } & \multicolumn{2}{|c|}{ Variable absent } & \multirow[t]{2}{*}{ Adjusted IRR $(95 \% \mathrm{Cl})$} \\
\hline & $\begin{array}{l}\text { No. of } \\
\text { epidemics }\end{array}$ & $\begin{array}{l}\text { Mean no. of } \\
\text { malaria cases }\end{array}$ & $\begin{array}{l}\text { No. of } \\
\text { epidemics }\end{array}$ & $\begin{array}{l}\text { Mean no. of } \\
\text { malaria cases }\end{array}$ & \\
\hline Control measure failure & 5 & 86.8 & 55 & 96.7 & $0.35(0.07-1.82)$ \\
\hline Population movement & 42 & 66.4 & 18 & 164.5 & $0.42(0.18-0.98)$ \\
\hline Natural disaster & 4 & 173.5 & 56 & 90.3 & $3.46(0.37-32.7)$ \\
\hline Drought & 4 & 116.8 & 56 & 94.3 & $0.24(0.03-1.90)$ \\
\hline Environmental manipulation & 4 & 91.8 & 56 & 96.1 & $1.11(0.18-6.74)$ \\
\hline Agricultural manipulation & 2 & 188.0 & 58 & 92.7 & $3.68(0.47-28.7)$ \\
\hline Rainfall & 36 & 139.6 & 24 & 30.1 & $3.64(1.64-9.06)$ \\
\hline Temperature & 46 & 101.0 & 14 & 78.8 & $1.31(0.28-6.12)$ \\
\hline Humidity & 44 & 93.2 & 16 & 103.0 & $0.34(0.08-1.36)$ \\
\hline Wind & 11 & 88.4 & 49 & 97.5 & $1.94(0.70-5.35)$ \\
\hline
\end{tabular}

$I R R=$ incidence rate ratio; $C I=$ confidence interval.

were higher in the southern parts of the province $[9,11]$. Higher temperatures in the south provide a longer period for local transmission to occur over the year [12]. This may be another reason accounting for the higher incidence of both epidemics and cases in the southern areas.

While the sensitivity of population movements as a predictor decreased in larger epidemics, the impact of rainfall as a predictor became higher as the size of the epidemics increased. This association was also confirmed when using the zero-truncated negative binomial model, indicating that the epidemics were unlikely to progress beyond a small outbreak if the environmental condition for transmission was not appropriate, even after the introduction of a new parasite through population movement. On the other hand, rainfall provides a favourable environment for epidemics to expand and affect more of the population. The sensitivity of humidity and temperature for either small or large epidemics was equally high, although these 2 factors have a limiting effect on malaria transmission. The epidemics, therefore, would not occur in their absence [13].

P. falciparum was reported in almost half of the studied epidemics. This prevalence was considerably higher than that found by Raeisi et al., who reported that $90 \%$ of malaria cases found in Islamic Republic of Iran between 2002 and 2007 were caused by P. vivax [8]. Similarly, Salehi et al. reported the prevalence of P. vivax to be as high as $81 \%$ in Sistan va Baluchestan province between 2005 and 2008 [9].P. falciparum malaria has a more severe natural course and has the potential to cause more deaths. On the other hand, P. vivax was found in almost every epidemic. It is accompanied by latent infection and relapse; therefore, incomplete treatment of the cases might activate previously inactive malaria foci and contribute to a new epidemic.

All except one of the epidemics investigated included indigenous cases. While the number of imported cases has reduced recently, about $20 \%$ of malaria cases found in Sistan va Baluchestan province are still classified as imported, mainly from Pakistan and Afghanistan [9]. Given that the environmental conditions are favourable for local transmission, introducing new cases would establish the transmission cycle, leading to an epidemic. However, the extent to which imported cases are responsible for flare-ups of epidemics is not exactly clear. Furthermore, as shown in Figure 1, the major epidemics occurred in districts adjacent to
Pakistan. As the malaria control programme was conducted in all regions of the province, it can be concluded that the source of some of the epidemics was in Pakistan.

Higher rainfall as well as higher temperatures and humidity were the main meteorological variables accompanying malaria epidemics in the present study. Population movement was seen in the majority of epidemics as well. While these findings were approved by many studies [12,14-19], the mechanisms by which these variables make the region susceptible to epidemics are not yet fully understood $[20,21]$. Salehi et al. reported a negative correlation between rainfall and the incidence of malaria in Sistan va Baluchestan province [11]. Although the annual rainfall decreases from north to south in the province, the presence of other factors such as being in the neighbourhood of Pakistan, cross-border movements and lower socioeconomic status are probable factors making the southern part of the province more susceptible to both higher malaria incidence and epidemics. Nevertheless, the correlation between the annual rainfall rate and malaria incidence should be differentiated from the sensitivity of rainfall in causing such epidemics. 
In conclusion, as the malaria epidemics were mainly small-scale, short outbreaks, the health system can respond to them if well prepared. On the other hand, considering the fact that the malaria control programme in the Islamic Republic of Iran is approaching its elimination phase, even short and small outbreaks occurring in scattered foci can create major obstacles to achieving the final targets of the programme. The high sensitivity of certain meteorological and vulnerability factors shows that developing a malaria early warning system based on these indices plays an important role in eliminating malaria from south-east Islamic Republic of Iran. An epidemic reporting and investigation system might provide the information required for developing and modifying the system after it is launched. However, further research is necessary to study the relationship between climatic and socioeconomic factors and the development of malaria epidemics and to determine the lead time for each variable before the epidemics occur.

\section{Acknowledgements}

We acknowledge the invaluable contribution by Mrs Leila Faraji, Mrs Fateme Nikpour, Mr. Mohammad Sakeni, and all the staff of the Deputy for Health of Zahedan University of Medical Sciences, for their help in accessing the data. The authors would like to acknowledge the financial support provided by United Nation Development Programme. This paper is a part of the $\mathrm{PhD}$ thesis in School of Public Health, Tehran University of Medical Sciences.

\section{References}

1. Strategic plan for malaria control and elimination in the $W H O$ Eastern Mediterranean Region 2006-2010. Cairo, World Health Organization Regional Office for the Eastern Mediterranean, 2007.

2. Edrissian G. Malaria in Iran: past and present situation. Iranian Journal of Parasitology, 2006, 1:1-14.

3. Malaria elimination, in I.R. Iran, horizon 1404. Volume 1. Tehran, Ministry of Health and Medical Education, 2009 [in Farsi].

4. Hook C. Field guide for malaria epidemic assessment and reporting, draft for field testing. Geneva, World Health Organization, 2004.

5. Malaria control in complex emergencies: an inter-agency field handbook. Volume 1. Geneva, World Health Organization, 2005.

6. Kiszewski AE, Teklehaimanot A. A review of the clinical and epidemiologic burdens of epidemic malaria. American Journal of Tropical Medicine and Hygiene, 2004, 71(Suppl.):128-135.

7. Prevention and control of malarial epidemics. Paper presented at the 3rd Meeting of the Roll Back Malaria Technical Support Network. Geneva, World Health Organization, 2002.

8. Raeisi A et al. The trend of Malaria in I.R. Iran from 2002 to 2007. Hakim Research Journal, 2009, 12:35-41.

9. Salehi $M$ et al. Analysis of malaria epidemic features in Sistan and Baluchistan province, southeast of Iran, 2005-2008. Iranian Red Crescent Medical Journal, 2010, 12:247-253.

10. Haghdoost AA, Alexander N, Cox J. Modelling of malaria temporal variations in Iran. Tropical Medicine and International Health, 2008, 13:1501-1508.

11. Salehi M et al. Spatial modeling of malaria incidence rates in Sistan and Baluchistan province, Islamic Republic of Iran. Saudi Medical Journal, 2008, 29:1791-1796.
12. Zhou G et al. Association between climate variability and malaria epidemics in the East African highlands. Proceedings of the National Academy of Sciences of the United States of America, 2004, 101:2375-2380.

13. Bhattacharya $\mathrm{S}$ et al. Climate change and malaria in India. Current Science, 90(3):369-375.

14. Jones AE et al. Climate prediction of El Niño malaria epidemics in north-west Tanzania. Malaria Journal, 2007, 6:162.

15. Devi NP, Jauhari RK. Climatic variables and malaria incidence in Dehradun, Uttaranchal, India. Journal of Vector Borne Diseases, 2006, 43:21-28.

16. Bi P et al. Climatic variables and transmission of malaria: a 12 -year data analysis in Shuchen County, China. Public Health Reports, 2003, 118:65-71.

17. Hay SI et al. Forecasting, warning, and detection of malaria epidemics: a case study. Lancet, 2003, 361:1705-1706

18. 18. Sharma VP, Srivastava A. Role of geographic information system in malaria control. Indian Journal of Medical Research, 1997, 106:198-204.

19. Bouma MJ, Dye C, van der Kaay HJ. Falciparum malaria and climate change in the northwest frontier province of Pakistan. American Journal of Tropical Medicine and Hygiene, 1996, 55:131-137.

20. Thomson MC, Connor SJ. Malaria early warning system: concepts, indicators and partners. Geneva, World Health Organization, 2000:50-53.

21. Cox J, Abeku TA. Early warning systems for malaria in Africa: from blueprint to practice. Trends in Parasitology, 2007, 23:243-246. 